\title{
Charge-Transfer Mechanism in Chlorophyll Derivative-based Biosolar Cells with Hole-Transporting P3HT Revealed by Sub-
}

\section{Picosecond Transient Absorption Spectroscopy}

Shengnan Duan ${ }^{\mathrm{a}}$, Li Wang ${ }^{\mathrm{b}}$, Wenjie Zhao ${ }^{\mathrm{a}}$, Jianbo Du', Lingyun Pan ${ }^{\mathrm{c}}$, Naoto Tamai ${ }^{\mathrm{b}}$, Shin-ichi Sasaki ${ }^{\mathrm{d}, \mathrm{e}}$, Hitoshi Tamiaki ${ }^{\mathrm{e}}$, Xiao-Feng Wang ${ }^{\mathrm{a}^{*}}$

${ }^{a}$ Key Laboratory of Physics and Technology for Advanced Batteries (Ministry of Education), College of Physics, Jilin University, Changchun, 130012, P. R. China.

${ }^{\mathrm{b}}$ Faculty of Science and Technology, Kwansei Gakuin University, Gakuen 2-1, Sanda, 669-1337, Hyogo, Japan.

${ }^{\mathrm{c}}$ College of Physics, Jilin University, Changchun, 130012, P. R. China.

${ }^{\mathrm{d}}$ Nagahama Institute of Bio-Science and Technology, Nagahama, Shiga, 526-0829, Japan.

${ }^{\mathrm{e}}$ Graduate School of Life Sciences, Ritsumeikan University, Kusatsu, Shiga, 525-8577, Japan

Corresponding author:

X.-F. Wang: xf_wang@jlu.edu.cn 


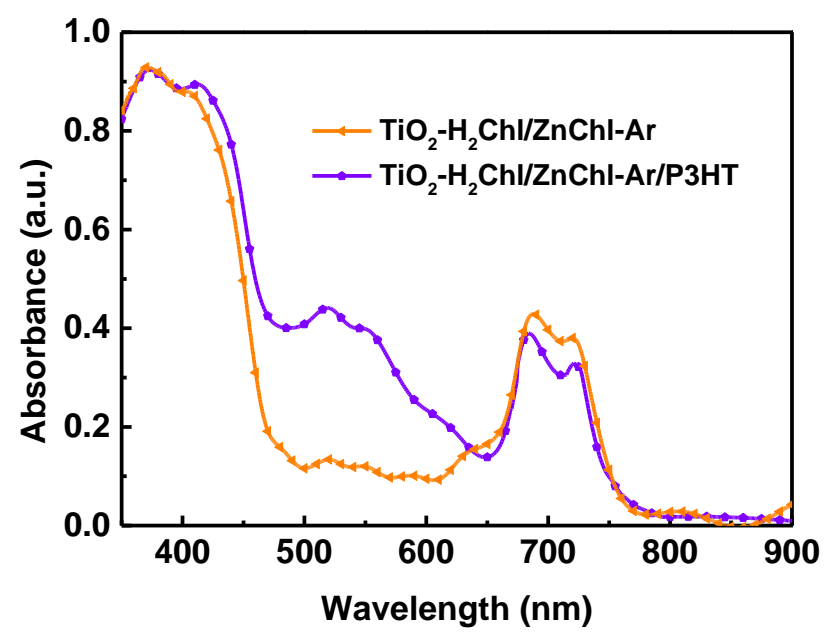

Figure S1. Steady-state absorption spectra of $\mathrm{TiO}_{2} / \mathrm{H}_{2} \mathrm{Chl} / \mathrm{ZnChl}$-Ar before and after spin-coating P3HT.
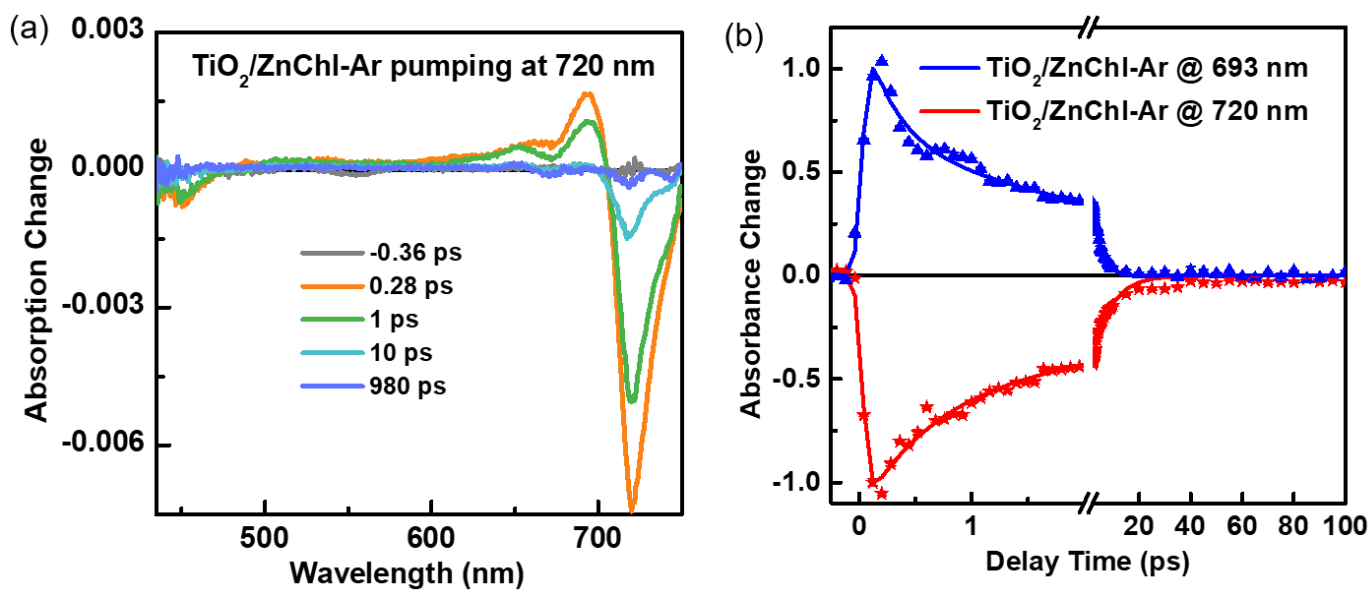

Figure S2. (a) The TAS decay signal and (b) kinetic trace of the $\mathrm{TiO}_{2} / \mathrm{ZnChl}-\mathrm{Ar}$ film pumped at $720 \mathrm{~nm}$. 


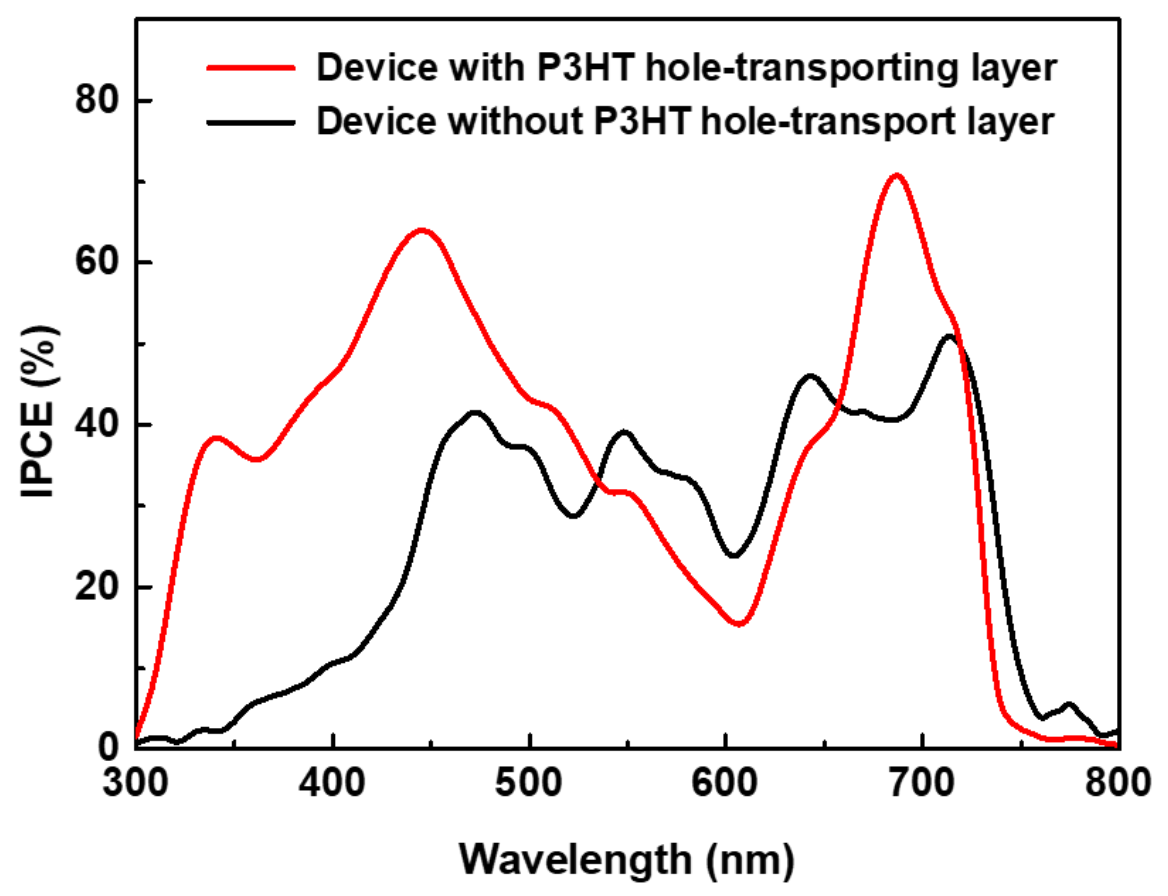

Figure S3. The monochromatic incident photon-to-electron conversion efficiency of the Chl derivatives-based devices with and without P3HT hole transporting layer.

Table S1. The fitted lifetimes of the $\mathrm{TiO}_{2} / \mathrm{ZnChl}-\mathrm{Ar}$ film at the wavelength of $693 \mathrm{~nm}$ and $715 \mathrm{~nm}$, respectively when pumped at $720 \mathrm{~nm}$.

\begin{tabular}{ccc}
\hline $\mathrm{TiO}_{2} / \mathrm{ZnChl}-\mathrm{Ar}$ film & $@ 693 \mathrm{~nm}$ & $@ 715 \mathrm{~nm}$ \\
\hline \multirow{2}{*}{ Pumped at $720 \mathrm{~nm}$} & $\tau_{1}=0.29 \pm 0.02 \mathrm{ps}$ & $\tau_{1}=0.69 \pm 0.05 \mathrm{ps}$ \\
& $\tau_{2}=3.08 \pm 0.29 \mathrm{ps}$ & $\tau_{2}=7.20 \pm 0.47 \mathrm{ps}$ \\
\hline
\end{tabular}

